doi: 10.17492/mudra.v3i2.7897

\title{
Functioning of Derivatives Market in India with Special Focus on Credit Derivatives
}

\author{
K V Bhanu Murthy*
}

\begin{abstract}
The derivatives market in India got a shot in the arm with the Government deciding to treat income from derivatives trading as a non-speculative income. The decision to treat income from derivative trading as a non-speculative income has contributed to an increase in the trading volume in the derivative market since it provides for setting off of derivative income/loss against normal income/loss. This paper looks at the functioning of the derivatives market along with special focus on credit derivatives. Since the early 1990s, there has been proliferation of different types of credit derivatives in several countries. We examine various forms of credit derivatives such as Credit Default Swap (CDS), Total Return Swap (TRS), and Credit Linked Note (CLN). The paper also analyses the benefits and risks involved in credit derivatives.
\end{abstract}

Keywords: Derivatives market; Credit derivatives; Credit Default Swap; Total Return Swap; Credit Linked Note.

\subsection{Introduction}

India has introduced different equity derivatives in a phased manner. This phased approach was adopted in India with index futures being introduced in June 2000, index options in June 2001 and individual stock options in July 2001.The Securities and Exchange Board of India (SEBI) set up a 24-member committee under the Chairmanship of L.C. Gupta on November 18, 1996 to develop appropriate regulatory framework for derivatives trading in India. The Committee submitted its report on March 17, 1998 prescribing necessary preconditions for introduction of derivatives trading in India. The Committee recommended that derivatives should be declared as securities so that regulatory framework applicable to trading of securities could also govern trading of derivatives ${ }^{1}$.

*Former Dean, Faculty of Commerce and Business, Delhi School of Economics, University of Delhi. (email: bhanumurthykv@yahoo.com) 
2 MUDRA: Journal of Finance and Accounting, Volume 3, Issue 2

The regulatory objectives as outlined out by the Committee have been reproduced below. "The Committee believes that regulation should be designed to achieve specific, well-defined goals. It is inclined towards positive regulation designed to encourage healthy activity and behaviour. It has been guided by the following objectives:

A. Investor protection: Attention needs to be given to the following four aspects:

- Fairness and transparency: The trading rules should ensure that trading is conducted in a fair and transparent manner. Experience in other countries shows that in many cases, derivative brokers/dealers failed to disclose potential risk to the clients. In this context, sales practices adopted by dealers for derivatives would require specific regulation. In some of the most widely reported mishaps in the derivatives market elsewhere, the underlying reason was inadequate internal control system at the userfirm itself so that overall exposure was not controlled and the use of derivatives was for speculation rather than for risk hedging. These experiences provide useful lessons for us for designing regulations.

- Safeguard for clients' moneys: Moneys and securities deposited by clients with the trading members should not only be kept in a separate clients' account but should also not be attachable for meeting the broker's own debts. It should be ensured that trading by dealers on own account is totally segregated from that for clients.

- Competent and honest service: The eligibility criteria for trading members should be designed to encourage competent and qualified personnel so that investors/clients are served well. This makes it necessary to prescribe qualification for derivatives brokers/dealers and the sales persons appointed by them in terms of a knowledge base.

- Market integrity: The trading system should ensure that the market's integrity is safeguarded by minimising the possibility of defaults. This requires framing appropriate rules about capital adequacy, margins, clearing corporation etc.

B. Quality of markets: The concept of 'quality of markets' goes well beyond market integrity and aims at enhancing important market qualities, such as cost-efficiency, price-continuity, and price-discovery.

C. Innovation: While curbing any undesirable tendencies, the regulatory framework should not stifle innovation which is the source of all economic progress, more so because financial derivatives represent a new rapidly developing area, aided by advancements in information technology".

\subsection{Derivative Products}

Derivatives products have been in India for quite some time now. Vashishtha and Kumar (2010) analyse the historical roots of derivative trading, types of derivative 
products, regulation and policy developments, trend and growth, future prospects and challenges of derivative market in India. They also discuss the status of global derivatives markets vis-a-vis the Indian derivatives market. Bhattacharya (2007) traces the evolution and development of the commodity derivatives market in India. She also outlines its infrastructure and regulation.

The major types of derivatives products have been described below.

\subsection{Interest and currency futures}

The Committee stated in Paragraph 1.24: "There are inter-connections among the various kinds of financial futures [equity, interest rate and currency], because the various financial markets are closely inter-linked, as the recent financial market turmoil in East and South-East Asian countries has shown. The basic principles underlying the running of future markets and their regulation are the same. Having a common trading infrastructure will have important advantages. The Committee, therefore, feels that the attempt should be to develop an integrated market structure".

\subsection{Single stock derivatives}

The Committee advocated a phased introduction of different equity derivatives in India in Paragraph 2.17 of its report: "The consensus in the Committee was that stock index futures would be the best starting point for equity derivatives in India. The Committee has arrived at this conclusion after careful examination of all aspects of the problem, including the survey findings and regulatory preparedness. The Committee would favour the introduction of other types of equity derivatives also, as the derivatives market grows and the market players acquire familiarity with its operations. Other equity derivatives include options on stock index or on individual stocks. There may also be room for more than one stock index futures. It is bound to be a gradual process, shaped by market forces under the over-all supervision of SEBI".

The Committee was not much inclined towards the fourth type of equity derivatives (individual stock futures) given its then limited popularity globally: "The fourth type, viz. individual stock futures, was favoured much less. It is pertinent to note that the US does not permit individual stock futures. Only one or two countries in the world are known to have futures on individual stocks". (Paragraph 2.3)

\subsection{Amendment of Securities Contract Regulation Act (SCRA)}

In pursuance of the recommendations of the L.C. Gupta Committee, SCRA was amended in December 1999 to include derivatives within the ambit of securities and the regulatory framework was developed for governing derivatives trading. The Act also made it clear that derivatives shall be legal and valid only if such contracts are traded on a recognised stock exchange, thus precluding OTC derivatives. The government also 
4 | MUDRA: Journal of Finance and Accounting, Volume 3, Issue 2

rescinded in March 2000, the three-decade old notification, which prohibited forward trading in securities.

Derivatives trading commenced in India in June 2000 after SEBI granted the final approval to this effect in May 2000. SEBI permitted the derivatives segments of two stock exchanges NSE and BSE, and their clearing house/corporation to commence trading and settlement in approved derivative contracts. To begin with, SEBI approved trading in index future contracts based on S\&P CNX Nifty and BSE-30 (Sensex) index. This was followed by approval for trading in options which commenced in June 2001 and the trading in options on individual securities commenced in July 2001. Future contracts on individual stocks were launched in November 2001. Trading and settlement in derivative contracts is done in accordance with the rules, by-laws, and regulations of the respective exchanges and their clearing house/corporation duly approved by SEBI and notified in the official gazette.

\subsection{Measures to Protect the Rights of Investors in the Derivatives Market}

Investors' money has to be kept separate at all levels and is permitted to be used only against the liability of the investor and is not available to the trading member or clearing member or even any other investor. A trading member is required to provide every investor with a risk disclosure document which will disclose the risks associated with the derivatives trading so that investors can take a conscious decision to trade in derivatives. Investors get the contract note duly time stamped for receipt of the order and execution of the order. The order is executed with the identity of the client and without client ID order is not accepted by the system. The investors can demand the trade confirmation slip with their respective ID in support of the contract note. This protects them from the risk of price favours, if any, extended by the Member.

In the derivatives market all money paid by the investors towards margins on all open positions is kept in trust with the clearing house/clearing corporation and in the event of default of the trading or clearing member the amounts paid by the client towards margins are segregated and not utilized towards the default of the member. However, in the event of default of a member, losses suffered by the investors, if any, on settled/closed out position are compensated from the investors' protection fund, as per the rules, by-laws and regulations of the derivative segment of the exchanges.

\subsection{Recent Developments in the Derivatives Market}

The derivatives market got a shot in the arm with the Government deciding to treat income from derivatives trading as a non-speculative income. The decision to treat 
income from derivative trading as a non-speculative income will contribute to an increase in trading volume in the derivative market since it provides for setting off of derivative income/loss against normal income/loss. FIIs are permitted to submit appropriate collateral, in cash or otherwise when trading in domestic derivatives. According to market players, this will bring about flexibility and encourage FIIs to take greater exposure through the derivative contracts. Local players already had the flexibility of submitting collaterals, such as bank guarantee or shares or deposit receipt, in place of cash or along with cash, for meeting their margin obligations.

\subsection{Credit Derivatives}

The credit derivatives are gaining increasing popularity in many countries. Since the early 1990s, there has been proliferation of different types of credit derivatives in several countries. A credit derivative is a contract (derivative) to transfer the risk of the total return on a credit asset falling below an agreed level, without transfer of the underlying asset. This is usually achieved by transferring risk on a credit reference asset. Early forms of credit derivatives were financial guarantees. Credit derivatives are designed to allow independent trading/hedging of credit risk. It is also possible to transfer and/or transform credit risk through securitisation. Credit derivative is a logical extension of two of the most significant developments in financial markets, viz., securitisation and derivatives.

There have been a number of studies that have examined the rationale, benefits and impact of credit derivatives. Alnassar and Chin (2015) investigate the reasons for the use of credit derivatives (CDs) by banks in risk management. his study provides an extensive review on the factors that influence the decision on the use of CDs by banks, as well as identify the theory that supports its use. Batten and Hogen (2002) offer an explanation of credit derivatives as a group of financial instruments having a common purpose being the managing of credit exposures, and thus credit or default risk. They brings together the range of features bearing upon the effective development of a market in these financial instruments. Duffee and Zhou (2001) model the effects on banks of the introduction of a market for credit derivatives; in particular, credit-default swaps. They find that the introduction of a credit-derivatives market is not necessarily desirable because it can cause other markets for loan risk-sharing to break down.

\subsection{Forms of credit derivatives}

Credit derivatives are instruments that transfer a part or all of the credit risk of an obligation (or a pool of obligations), without transferring the ownership of the 
6 | MUDRA: Journal of Finance and Accounting, Volume 3, Issue 2

underlying asset(s). This is usually achieved by transferring risk on a credit reference asset. Three common forms of credit derivatives are credit default swap (CDS), total return swap (TRS) and credit linked note (CLN).

A. Credit Default Swap (CDS): A CDS consists of swapping, usually on an ongoing basis, the risk premium inherent in an interest rate on a bond or a loan in return for a cash payment that is made in the event of default by the debtor. The CDS has become the main driver of the credit derivatives market, offering liquid price discovery and trading on which the rest of the market is based. It is an agreement between a protection buyer and a protection seller, whereby the buyer pays a periodic fee in return for a contingent payment by the seller upon a credit event happening in the reference entity. The contingent payment usually replicates the loss incurred by creditor of the reference entity in the event of its default. It covers only the credit risk embedded in the asset, risks arising from other factors, such as interest rate movements, remain with the buyer.

B. Total Return Swap (TRS): A TRS (also known as total rate of return swap) is a contract between two counterparties, whereby they swap periodic payments for the period of the contract. Typically, one party receives the total return (interest payments plus any capital gains or losses for the payment period) from a specified reference asset, while the other receives a specified fixed or floating cash flow that is not related to the creditworthiness of the reference asset, as with a vanilla interest rate swap. The payments are based upon the same notional amount. The reference asset may be any asset, index or basket of assets. The TRS is simply a mechanism that allows one party to derive the economic benefit of owning an asset without use of the balance sheet, and which allows the other to effectively buy protection against loss in value due to ownership of credit assets. While the CDS provides protection against specific credit events, the TRS protects against the loss of value irrespective of cause, whether default and widening of credit spreads, among others.

C. Credit Linked Note $(C L N)$ : A CLN is an instrument whose cash flow depends upon a credit event, which can be a default, credit spread, or rating change. The definition of the relevant credit events must be negotiated by the parties to the note. A CLN, in effect, combines a credit-default swap with a regular note (with coupon, maturity, redemption). Given its regular-note features, a CLN is an on-balance sheet asset, unlike a CDS.

\subsection{Significance of credit derivatives}

Credit derivative markets are most active where credit quality measurement and rating systems are transparent and have widespread adoption as in North America and Europe. In addition, the demand for structured credit products in Asia and the Middle East has been growing. The rapid pace of growth and widespread participation in the 
credit derivatives market in several countries has transformed the financial landscape. Credit derivatives have significance for both banks and investors in mitigating credit risk. For instance, a commercial bank can use credit derivatives to manage the risk of its loan portfolio and an investment bank can use credit derivatives to manage the risks it incurs when underwriting securities. Investors - such as an insurance company, asset manager, or hedge fund - can use credit derivatives to align its credit risk exposure with its desired credit risk profile.

Credit derivatives in international markets have effectively helped to enhance the efficiency of the financial system by providing to both bank and non-bank financial institutions access to a broader range of risk-return combinations and a wider pool of underlying risks and enhancing the liquidity of corporate bond markets. The information revealed through credit derivative mechanism is very useful for supervision and market surveillance.

\subsection{Benefits of credit derivatives}

Banks and the financial institutions derive at least three main benefits from credit derivatives:

a) Credit derivatives allow banks to transfer credit risk and hence free up capital, which can be used for other productive purposes.

b) Banks can conduct business on existing client relationships in excess of exposure norms and transfer away the risks. For instance, a bank which has hit its exposure limits with a client group may have to turn down a lucrative guarantee deal. However, with credit derivatives, the bank can take up the guarantee and maintain its exposure limits by transferring the credit risk on the guarantee or previous exposures. This allows bank to maintain client relationships.

c) Banks can construct and manage a credit risk portfolio of their own choice and risk appetite unconstrained by funds, distribution and sales effort.

\subsection{Risks involved in credit derivatives}

Credit derivatives pose risk management challenges of their own. Credit derivatives can transform credit risk in intricate ways that may not be easy to understand. Complex credit derivatives rely on complex models, leading to model risk. Credit rating agencies interpret this complexity for investors, but their ratings can be misunderstood, creating rating agency risk. The settlement of a credit derivative contract following a default can have its own complications, creating settlement risk. Apart from these risks, the credit risk remains the core risk in the credit derivative segment. The use of credit derivative instruments has changed the underlying borrower-lender relationship and established 
8 |MUDRA: Journal of Finance and Accounting, Volume 3, Issue 2

new relationships between lenders that become risk shedders and the new risk takers. This new relationship has the potential for market failure due, for instance, to asymmetric information. The growth of hedge funds, particularly credit-oriented hedge funds, has accelerated market development and credit risk dispersion. While credit derivative markets increasingly facilitate the primary transfer of credit risk, secondary market liquidity is still lacking within some segments, creating the potential for market disruptions. As such, these markets are subject to increased attention from supervisors and policymakers and raise some supervisory concerns.

In short, the use of credit derivatives raises the following concerns:

a) Some of the credit derivatives, which are being used, are at their infancy and need to mature. Introduction of such products, therefore, may be potentially destabilising.

b) Measurement and management of credit risk is more complicated than market risk.

c) Documentation risk is an important aspect of credit derivatives.

d) Certain incentive issues arise with the use of credit derivatives. This is because such instruments typically change the underlying borrower-lender relationship and establish new relationships between lenders that become risk shedders and the new risk takers. This new relationship has the potential for market failure due, for instance, to asymmetric information.

\subsection{Credit derivatives and Sub-prime crisis of 2007}

The role that credit derivatives played in the 2007 sub-prime crisis is well-known. The macroeconomic environment with a prolonged period of low interest rates, high liquidity and low volatility led to underestimation of risks by financial institutions, breakdown of credit and risk management practices in many financial institutions, and shortcomings in financial regulation and supervision. Banks, especially in the US, increasingly turned to 'originate and distribute' model in which they bundled and sold standardised mortgages as securities. Though favourable credit ratings were obtained for most of these bundled securities by carefully structuring their priority in receiving cash flow from servicing of the original portfolio, many of these were in reality sub-prime securities. As housing prices in the US declined, the defaults rose in several leading international banks. The kind of problems witnessed in the US sub-prime mortgage market can also surface in other types of lending such as leveraged loans and consumer credit. Furthermore, such problems may not confine to industrial countries, but can surface in other emerging economies as well where financial institutions take excessive risks in the wake of weak lending practices, and where regulatory and supervisory frameworks are found to be inadequate.

The unbridled proliferation of complex credit derivatives and excessive risk transfer by adoption of the originate-to-distribute model is recognised as one of the root causes of 
the current financial crisis. The recent credit turmoil has also underscored the importance of liquidity risk arising from off-balance sheet commitments, implicit or explicit, of the credit intermediaries. While the development of markets for credit derivatives and asset securitization products can play a critical role in furthering economic growth, this requires to be pursued in a gradual manner by sequencing reforms and putting in place appropriate safeguards before introducing such products.

\subsection{Credit derivatives in India}

The credit market refers to the market where financial instruments that embrace credit risk are traded. In addition to traditional instruments, such as loans and advances, corporate bonds, and commercial papers the credit market now includes securitised products in which various credit risks have been pooled as well as credit derivatives whose underlying assets encompass credit risks. As a financial system which is dominated by bank intermediation, credit has traditionally been the main source of funds to various sectors in the Indian economy, and loans and advances continue to be the preferred part of asset books of banks. However, the implementation of risk management guidelines and the requirement for providing a capital charge for credit risk in the balance sheet has given banks an incentive to look for innovative methods of transferring credit risk from their books.

While simple techniques for transferring credit risk, such as financial guarantees, collateral and credit insurance have long been prevalent in the Indian banking industry, the recent innovative instruments in credit risk transfer are yet to make an impact. However, in recent years the risk management architecture of banks in India has strengthened and they are on the way to becoming Basel II compliant, providing adequate comfort level for the introduction of credit derivatives. The Reserve Bank in its Annual Policy announced in April 2007 mentioned that as part of the gradual process of financial sector liberalization in India, it was considered appropriate to introduce credit derivatives in a calibrated manner. Furthermore, the amendment to the Reserve Bank of India Act, 1934 had provided legality to OTC (over the counter) derivative instruments, including credit derivatives.

Although derivative instruments were introduced in July 1999 in the money/foreign exchange market in the form of forward rate agreements (FRAs) ${ }^{2}$ and interest rate swaps $(\text { IRS })^{3}$, credit derivatives are yet to be introduced. The RBI's Annual Policy Statement 2007-08 announced the introduction of credit derivatives in India in a calibrated manner. In view of certain adverse developments in the international financial markets, especially credit markets, resulting from recent financial turmoil, it was widely felt that time is not opportune to introduce the credit derivatives in India for the present. As such, the RBI 
announced on June 19, 2008 its decision to keep in abeyance the issuance of the final guidelines on introduction of credit derivatives in India.

\subsection{Traders and Trading System of Derivatives}

\subsection{Traders in derivatives market}

The traders in derivatives market include the hedgers, speculators and arbitrageurs.

A. Hedgers: Hedgers are the traders who wish to eliminate the risk (of price change) to which they are already exposed. They may take a long position on, or short sell, a commodity and would, therefore, stand to lose should the prices move in the adverse direction. The trader can sell future (or forward) contracts with a matching price, to hedge. Stocks carry two types of risk: company specific and market risk. While company risk can be minimised by diversifying your portfolio, market risk cannot be diversified but has to be hedged. Hedging involves protecting an existing asset position from future adverse price movements. In order to hedge a position, a market player needs to take an equal and opposite position in the futures market to the one held in the cash market.

B. Speculators: If hedgers are the people who wish to avoid the price risk, speculators are those who are willing to take such risk. These are the people who take position in the market and assume risks to profit from fluctuations in prices. In fact, the speculators consume information, make forecasts about the prices and put their money in these forecasts. Depending on their perceptions, they may take long or short positions on futures and/or options, or may hold spread positions (simultaneous long and short positions on the same derivatives). Speculators are those who do not have any position on which they enter in futures and options market. They only have a particular view on the market, stock, commodity etc. In short, speculators put their money at risk in the hope of earning profit from an anticipated price change. They consider various factors such as demand, supply, market position, open interests, economic fundamentals and other data to take their positions.

C. Arbitrageurs: Arbitrageurs thrive on market imperfections. An arbitrageur profits by trading a given commodity, or other item, that sells for different prices in different markets. This becomes possible by simultaneous purchase of securities in one market where the price is low and sale in another market, where the price is comparatively higher. This is done when the same securities are being quoted at different prices in the two markets. Arbitrageurs derive advantage from difference in prices of securities prevailing in the two markets. An arbitrageur is basically risk averse. He enters into those contracts were he can earn riskless profits. When markets are imperfect, 
buying in one market and simultaneously selling in other market gives riskless profit. Arbitrageurs are always in the lookout for such imperfections. In the futures market one can take advantages of arbitrage opportunities by buying from lower priced market and selling at the higher priced market. In index futures arbitrage is possible between the spot market and the futures market.

\subsection{Trading system}

A. National Exchange for Automated Trading (NEAT-F\&O): Futures and options trading system of NSE - called NEAT-F\&O trading system - provide a fully automated screen-based trading for index futures and options, stock futures and options and futures on interest rate on a nationwide basis as well as an online monitoring and surveillance mechanism. It supports an order driven market and provides complete transparency of trading operations. It is similar to that of trading of equities in the cash market segment. The software for the $\mathrm{F} \& \mathrm{O}$ market has been developed to facilitate efficient and transparent trading in futures and options instruments. Keeping in view the familiarity of trading members with the current capital market trading system, modifications have been introduced in the existing capital market trading system so as to make it suitable for trading futures and options.

B. Trading Mechanism: The NEAT-F\&O system supports an order driven market, wherein orders match automatically. Order matching is essentially on the basis of security, its price, time and quantity. All quantity fields are in units and price in rupees. The lot size on the futures and options market is 50 for Nifty. The exchange notifies the regular lot size and tick size for each security traded on this segment from time to time. Orders, as and when they are received, are first time stamped and then immediately processed for potential match. When any order enters the trading system, it is an active order. If it finds a match, a trade is generated. If a match is not found, then the orders are stored in different books. Orders are stored in price-time priority in various books in the following sequence: (a) best price, and (b) within price, by time priority.

C. Entities in the Trading System: There are four entities in the trading system:

a) Trading members: Trading members are members of NSE. They can trade either on their own account or on behalf of their clients including participants. The exchange assigns ID to each trading member. Each trading member can have more than one user.

b) Clearing members: Clearing members are members of NSCCL. They carry out risk management activities and confirmation/inquiry of trades through the trading system.

c) Professional clearing members: Professional clearing members are clearing 
12 | MUDRA: Journal of Finance and Accounting, Volume 3, Issue 2

members who are not trading member. Typically, banks and custodians become professional clearing members and clear and settle for their trading members.

d) Participants: A participant is a client of trading members like financial institutions. These clients may trade through multiple trading members but settle through a single clearing member.

D. Corporate Hierarchy: In the F\&O trading software, a trading member has the facility of defining a hierarchy amongst users of the system. This hierarchy comprises corporate manager, branch manager and dealer.

a) Corporate Manager: The term corporate manager is assigned to a user placed at the highest level in a trading firm. Such a user can perform all the functions such as order and trade-related activities, receiving reports for all branches of the trading member firm and also all dealers of the firm. Additionally, a corporate manager can define exposure limits for the branches of the firm. This facility is available only to the corporate manager.

b) Branch Manager: The branch manager is a term assigned to a user who is placed under the corporate manager. Such a user can perform and view order and traderelated activities for all dealers under that branch.

c) Dealer: Dealer is a user at the lower level of the hierarchy. A dealer can perform trade-related activities only for himself and does not have access to information on other dealers under either the same branch or other branches.

\subsection{Order types and conditions}

The system allows the trading members to enter orders with various conditions attached to them as per their requirements. These conditions are broadly divided into the following three categories:

A. Time Conditions: These include the following:

(i) Day order: A day order, as the name suggests, is an order which is valid for the day on which it is entered. If the order is not executed during the day, the system cancels the order automatically at the end of the day.

(ii) Immediate or Cancel (IOC): An IOC order allows the user to buy or sell a contract as soon as the order is released into the system, failing which the order is cancelled from the system. Partial match is possible for the order, and the unmatched portion of the order is cancelled immediately.

\section{B. Price Conditions}

(i) Stop-loss: This facility allows the user to release an order into the system, after the market price (last traded price) of the security reaches or crosses a threshold price, e.g. if for stop-loss buy order, the trigger is 1027, the limit price is 1030 and the market (last 
traded) price is 1023 , then this order is released into the system once the market price reaches or exceeds 1027. This order is added to the regular lot book with time of triggering as the time stamp, as a limit order of 1030. For the stop-loss sell order, the trigger price has to be greater than the limit price.

\section{Other Conditions}

(i) Market Price: Market orders are orders for which no price is specified at the time the order is entered (i.e. price is market price). For such orders, the system determines the price.

(ii) Limit Price: Price of the order after triggering from stop loss book.

(iii) Pro: Pro means that the orders are entered on the trading member's own account.

(iv) Cli: Cli means that the trading member enters the orders on behalf of a client.

(v) Trigger Price: It is the price at which an order gets triggered from stop-loss book. Several combinations of the above are allowed thereby providing enormous flexibility to the users.

\subsection{Market watch}

The purpose of market watch is to allow continuous monitoring of contracts or securities that are of specific interest to the user. It displays trading information for contracts selected by the user. The user also gets a broadcast of all the cash market securities on the screen. This function is also available if the user selects the relevant securities for display on the market watch screen. Display of trading information related to cash market securities is in read only format, i.e. the dealer can only view the information on cash market but cannot trade in them through the system. This is the main window from the dealer's perspective.

\subsection{Placing orders on the trading system}

While entering orders on the trading system-for both futures and the options market—members are required to identify orders as being proprietary or client orders. Proprietary orders should be identified as Pro and those of clients should be identified as Cli. Apart from this, in the case of $\mathrm{Cli}$ trades, the client account number should also be provided. The futures and options market is a zero sum game, i.e. the total number of long in contracts always equals the total number of short in contracts. The total number of outstanding contracts (long/short) at any point in time is called the open interest. This open interest figure is a good indicator of the liquidity in the contract. Based on studies carried out in international exchanges, it is found that open interest is maximum in near month expiry contracts. 
14 | MUDRA: Journal of Finance and Accounting, Volume 3, Issue 2

\subsection{Eligibility criteria for securities/indices traded in F\&O}

\section{A. Eligibility criteria for stocks}

- The stock is chosen from amongst the top 500 stocks in terms of average daily market capitalisation and average daily traded value in the previous 6 months on a rolling basis.

- A stock's median quarter-sigma order size over the last 6 months should not be less than Rs. 1 lakh. For this purpose, a stock's quarter-sigma order size should mean the order size (in value terms) required to cause a change in the stock price equal to onequarter of a standard deviation.

- The market wide position limit in the stock should not be less than Rs. 50 crore. The market wide position limit (number of shares) is valued taking into account the closing prices of stocks in the underlying cash market on the date of expiry of contract in the month. The market wide position limit of open position (in terms of the number of underlying stock) on futures and option contracts on a particular underlying stock should be lower of 20 percent of the number of shares held by nonpromoters in the relevant underlying security i.e. free-float holding.

If an existing security fails to meet the eligibility criteria for 3 months consecutively, then no fresh month contract will be issued on that security. However, the existing unexpired contracts can be permitted to trade till expiry and new strikes can also be introduced in the existing contract months.

For unlisted companies coming out with initial public offering, if the net public offer is Rs. 500 crore or more, then the exchange may consider introducing stock options and stock futures on such stocks at the time of its listing than in cash market.

B. Eligibility criteria for indices: The exchange may consider introducing derivative contracts on an index if the stocks contributing to 80 percent weightage of the index are individually eligible for derivative trading. However, no single eligible stock in the index should have a weightage of more than 5 percent in the index. The above criteria is applied every month, if the index fails to meet the eligibility criteria for 3 months consecutively, then no fresh month contract would be issued on that index.

\section{Eligibility criteria for stocks for derivatives trading on account of corporate} restructuring: The criteria in this case are as under:

a) All the following conditions shall be met in the case of shares of a company undergoing restructuring through any means for eligibility to reintroduce derivative contracts on that company from the first day of listing of the post- restructured company's stock in the underlying market:

- Futures and options contracts on the stock of the original (pre-restructure) company were traded on any exchange prior to its restructuring. 
- Pre-restructured company had a market capitalisation of at least`1,000 crore prior to its restructuring.

- Post-restructured company would be treated like a new stock and if it is, in the opinion of the exchange, likely to be at least one-third the size of the pre-restructured company in terms of revenues, or assets, or (where appropriate) analyst valuations.

- In the opinion of the exchange, the scheme of restructuring does not suggest that the post-restructured company would have any characteristic (for example extremely low free float) that would render the company ineligible for derivatives trading.

b) If the above conditions are satisfied, then the exchange takes the following course of action in dealing with the existing derivative contracts on the pre-restructured company and introduction of fresh contracts on the post- restructured company:

- In the contract month in which the post-restructured company begins to trade, the exchange introduces near month, middle month and far month derivative contracts on the stock of the restructured company.

- In subsequent contract months, the normal rules for entry and exit of stocks in terms of eligibility requirements would apply. If these tests are not met, the exchange shall not permit further derivative contracts on this stock and future month series shall not be introduced.

To sum up, financial derivatives are of recent origin in India, barring trade-related forward contracts in the forex market. Over the counter (OTC) as well as exchangetraded derivatives have been introduced, marking an important development in the structure of financial markets in India. Forward contracts in the forex market have also been liberalised. OTC derivatives, viz. interest rate swaps (IRS) and forward rate agreements (FRAs) were introduced in July 1999. The IRS and FRA were introduced with a view to deepening the money market as also to enable banks, primary dealers and financial institutions to hedge interest rate risks.

\section{Endnotes}

1. SEBI also set up a group in June 1998 under the chairmanship of Professor J.R. Varma, to recommend measures for risk containment in derivatives market in India. The report, which was submitted in October 1998, worked out the operational details of margining system, methodology for charging initial margins, net worth of brokers, deposit requirements and real-time monitoring requirements.

2. The FRA is an off-balance sheet contract between two parties under which one party agrees on the start date for trade and the party that agrees, would lodge a notional deposit with the other for a specified sum of money for a specified period of time (the FRA period) at a specified rate of interest (the contract rate). The party that has agreed to make the notional 
16 | MUDRA: Journal of Finance and Accounting, Volume 3, Issue 2

deposit has, thus, sold the FRA to the other party who has bought it.

3. The IRS is a contract between two counter-parties for exchange interest payment for a specified period based on a notional principal amount. The notional principal is used to calculate interest payments, but is not exchanged. Only interest payments are exchanged.

\section{References}

Alnassar, Walaa, \& Chin, Othman Bin. (2015). Why banks use credit derivatives? Review paper. Procedia Economics and Finance, 26: 566-574.

Bhattacharya, Himadri. (2007). Commodity derivatives market in India. Economic and Political Weekly, 42(13).

Vashishtha, Ashutosh \& Kumar, Satish. (2010). International Research Journal of Finance and Economics, 37.

Batten, J. \& Hogan, W. (2002). A perspective on credit derivatives. International Review of Financial Analysis, 11(3): 251-278.

Duffee, G. \& Zhou, C. (2001). Credit derivatives in banking: Useful tools for managing risk? Journal of Monetary Economics, 48(1): 25-54. 